\title{
Re: Intracaval and Intracardiac Extension of Wilms' Tumor. The Influence of Preoperative Chemotherapy on Surgical Morbidity
}

\author{
Lilian M. Cristofani, Ricardo J. Duarte, Maria T. Almeida, Vicente Odone Filho, Joao G. Maksoud, \\ Miguel Srougi
}

Pediatric Oncology (LMC, MTA, VOF), Pediatric Surgery (JGM) and Urology (RJD, MS), University of Sao Paulo Medical School, Sao Paulo, SP, Brazil

Int Braz J Urol, 33: 683-689, 2007

To the Editor:

Wilms tumor (WT) or nephroblastoma is the most common tumor of renal origin found in children. It accounts for $6 \%$ of all pediatric tumors and is the second most frequent intrabdominal solid organ tumor found in children. Initial survival rates in the early part of the last century were only $30 \%$, but now longterm survival is approaching $85 \%$ with many low stage tumors significantly higher (1-3). Despite the success there are several challenging clinical scenario's that face treating physicians. One problem, which is the subject of the article by Cristofani and colleagues, addresses the best method to treat a child with a Wilms tumor that extends into the inferior vena cava or up to the right atrium.

Wilms tumors may extend through the renal vein into the inferior vena cava and up to the atrium. In large published series, caval extension was reported between $2 \%$ and $5 \%$ and atrial extension in $0.2 \%$ to $1.2 \%$ of children with Wilms Tumor (4-6). There are two primary treatment strategies to treating a child with Wilms tumor. The first utilizes upfront nephrectomy followed by chemotherapy, the second employs pre-nephrectomy chemotherapy (7). To date no randomized studies have been conducted to guide definitive therapy in a patient with caval or atrial extension. Nevertheless, several publications including the series presented in this edition of the International Braz $\mathbf{J}$ Urol help guide therapy. The central treatment problem is defining who should undergo primary nephrectomy and removal of the vascular extension of tumor and who would benefit from pre-nephrectomy chemotherapy. The potential benefits for preoperative chemotherapy include possibility of resolution of thrombus, partial/complete response of thrombus, decreasing the need for cardiopulmonary bypass surgery and bleeding. The potential drawbacks include tumor emboli, tumor progression, a marginal reduction in complications and the recognized increased difficulty of removing a tumor from the venal cava or atria following chemotherapy.

In addition to Cristofani's paper, three large series provide insight to managing a child with vascular extension $(4,6,8)$. The International Society of Pediatric Oncology (SIOP) 93-01 GPOH study and the United Kingdom Children's Cancer Study Group UKW3 utilized preoperative chemotherapy as the primary mode of therapy. In the SIOP study, 33 of 1151 patients had vascular extension. In nine, there was extension into the atrium. Twenty-nine underwent preoperative chemotherapy. Twenty $(69 \%)$ responded to chemotherapy including one of those with extension into the atria. Nine required cardiopulmonary bypass to remove the tumor. There were no surgical deaths. In the UKW3 trial 59 patients had vascular extension with 10 extending into the atria. Fifty-two underwent preoperative chemotherapy with $35(67 \%)$ responding. Unfortunately 5/52 (10\%) died at operation due to uncontrolled bleeding. The National Wilms Tumor Study Group \#4 trial reported 
outcomes on 134 with vena cava or vascular extension. Unlike the two previous trials where prenephrectomy chemotherapy was the treatment of choice the initial treatment was left up to the individual treating physicians. In this report 69 received preoperative chemotherapy. Seventy-one percent had some response to therapy. In five cases a tumor embolism and progression was noted with three patients developing acute respiratory distress syndrome. When all the complications of therapy were considered, including those that occurred during the interval of preoperative chemotherapy the incidence of complications among those receiving preoperative therapy was not statistically different from the incidence among those who underwent primary resection. Although the overall complications were similar the majority of children responded to chemotherapy. The compelling response rate of the thrombus to chemotherapy has lead the Children's Oncology Group (formerly the NWTS) to recommend that preoperative chemotherapy be given to all patients with tumor extension above the hepatic cava.

Cristofani and colleagues present 16 patients over twenty-two years with vascular extension. The clinical outcomes of these patients are outstanding, one of the highest reported in the literature. This paper is helpful because both treatment strategies were used and evaluated. This study joins others in the literature showing an excellent response (72\%) to chemotherapy. In one of the cases tumor extension to the atria resolved and cardiopulmonary bypass was not need.

The most important comment that the authors make is that these children need to be treated by a multidisciplinary team. These are difficult high-risk patients. Preoperative chemotherapy is warranted but tumor embolism may occur and these children need to be watched very carefully. Finally, although the tumor may shrink, morbidity and mortality are significant as noted in the SIOP, UKW3 and NWTS4 reports. These cases require an experienced team of physicians to guide therapy to ensure maximum outcomes with minimal morbidity.

\section{REFERENCES}

1. Grundy PE, Green DM, Coppes MJ, Breslow N, Ritchey ML, Perlman EJ, et al.: Renal Tumors. In: Pizzo PA, Poplack DG (eds), Principles and Practice of Pediatric Oncology. Philadelphia, Lippincott Williams \& Wilkins. 2006: 865-93.

2. Gurney JG, Severson RK, Davis S, Robinson LL: Incidence of cancer in children in the Unitted States: sex -,race-, and 1-year ge specific rates by histologic type. Cancer. 1995; 75: 2186-95.

3. Kalapurakal JA, Dome JS, Perlman EJ, Malogolowkin M, Haase GM, Grundy PE, et al.: Management of Wilms' tumour: current practice and future goals. Lancet Oncol. 2004; 5: 37-46.

4. Lall A, Pritchard-Jones K, Walker J: Wilms' tumor with intracaval thrombus in the UK Children's Cancer Study Group UKW3 trial. J Pediatr Surg. 2006; 41: 382-7.

5. Shamberger RC, Guthrie KA, Ritchey ML, Haase G, Taskashima BA, Beckwith JB, et al.: Surgery related factors and local reccurance of Wilms tumor in the national Wilms tumor study 4. Ann Surg. 1999; 229: 292-7.

6. Szavay P, Luithle T, Semler O: Surgery of cavoatrial tumor thrombus in neprhobastoma: a report of the SIOP/GPOH study. Pediatr Blood Cancer. 2004; 4: 405.

7. Grundy PE, Perlman EJ, Ehrlich PF: Current issues in Wilms tumor management. Cur Prob Cancer. 2005; 29: 221-60.

8. Shamberger RC, Ritchey ML, Aase G, Bergemann TL, Loechelt-Yoshioka T, Breslow N, et al.: Intravascular extension of Wilms tumor. Ann Surg. 2001; 234; 11621.

Dr. Peter F. Ehrlich

Associate Professor of Surgery University of Michigan

Vice Chair Surgery Renal Tumors Committee Childrens Oncology Group Ann Arbor, MI, USA

E-mail:pehrlich@med.umich.edu 